\title{
Mobility at Retirement: A New Life Purpose Operating Social Justice Projects in Cambodia, Myanmar and Laos
}

\author{
Dr. Claudia Bell* \\ Department of Sociology, University of Auckland, New Zealand
}

\section{*Corresponding Author}

Dr. Claudia Bell

\author{
Article History \\ Received: 04.02.2020 \\ Accepted: 11.02.2020 \\ Published: 20.02.2020
}

\begin{abstract}
Stereotypical expectations of western retirees run counter to the goals and actions of the participants in this study. Dissatisfied at conditions available to them in their home countries, they escaped to Cambodia, Myanmar or Laos. There, they created new roles for themselves, advancing the wellbeing of disadvantaged local people. They set up grassroots ventures to upskill, house, educate and employ individuals otherwise bypassed for such opportunities. Fieldwork for this research took place in Cambodia, Myanmar and Laos in 2015, 2016 and 2019. Twenty projects were visited, including eco-tour guiding, food production, hospitality, and artisanal enterprises. For the operators, the emphasis is responsible, small-scale development, foregrounding a social justice agenda, to engage deprived members of the population. Through these micro aid initiatives local people, marginalised and disempowered because of disability, sex abuse, HIV Aids, and poverty, develop skills for employment. These runaway retirees are making a significant contribution in their new locations.
\end{abstract}

Keywords: Western retirees, Aid, humanitarian, Myanmar, Laos, Cambodia.

\section{INTRODUCTION}

Themes that are usually examined separately are addressed in this paper: ageing, mobility and social justice entrepreneurship. The Western retirees in this study have escaped expectations about ageing, as prescribed in their own cultures. Put simply: they have run away. Critical of their own nation's politics, and the limited social experiences for older citizens, they are fulfilling an urge to spend their last active years making an important contribution to the world. Relocation provides the next stage of their life journey. In a new environment very different to their original home, they have found a meaningful purpose in life. Their capacity to do this places them in the category of 'privileged migrants'. They are from the Global North, and advantaged by citizenship, class and race [1].

Positive experience of ageing is a 'persistent priority in ageing research' [2]. A Finnish study indicates that for their citizens, 'most women and men report high levels of life satisfaction in retirement regardless of their commitments to paid work... Health, finances, marital status, occupation, and voluntariness of retirement are the main factors that affect the satisfaction, subjective well-being, and mental health' [3]. This cannot be assumed to be the case in all western nations. For retirees for whom of all these elements are positive, this is referred to as 'successful aging' [4]. The term is commonly used in relation to maintaining good health and a positive outlook in the later years. This includes active engagement with life, and 'the functional ability that enables wellbeing in older age' [5]. Purpose in life has been summed up as having goals, a sense of direction, having aims, aspirations and objectives, doing good for others, knowing they are needed, and achieving a sense of accomplishment [6].

Those authors (above), and others, also acknowledge that for some retirees there may be a sense of rolelessness; of an unfulfilled need for significant engagement [7]. Loneliness is an oft-cited condition for older people. 'Meaningful relationships are regarded as the basis of a good and dignified life, and the lack of them as a risk for loneliness. Generally, our findings reflect loneliness experienced in a individualistic society' [8]. In a 1997 study, Ardelt suggested

Copyright @ 2020: This is an open-access article distributed under the terms of the Creative Commons Attribution license which permits unrestricted use, distribution, and reproduction in any medium for non commercial use (NonCommercial, or CC-BY-NC) provided the original author and source are credited. 
that 'psycho social development has a stronger influence on life satisfaction than objective circumstances'; that that happy, fulfilled aging was associated with 'both one's development and one's social pathways' [9]. Implicitly, this indicates that those feeling they are stuck in some kind of unhappy dead-end would do better to seek a new direction. But this is not always practicable. In order to realise mobility, individuals need to 'overcome distances, possess sufficient physical and mental strength... have relevant skills and knowledge... access to pensions, and rights to reside in a certain place' [10]. Yet this is precisely the action of the participants in this study. They have managed to shuck off the supposition that as ageing individuals, they must have 'constrained agency to improve their lives outside the country of origin' [10].

The retirees discussed in this paper have moved to developing countries, and set up their own social justice projects. Their initiatives encompass compassion and solidarity 'with people less fortunate in the international community... (Their projects) aspire to connect quite distinct worlds: the developed and the developing, the peaceful and the conflict ridden, and the democratic and the undemocratic' [11]. They are 'drivers of cross- border transfers of knowledge and skills,' a small, adaptable segment of migration [1]. This sector is totally independent; it does not receive financial or other support, either governmental or from any international aid agencies [12]. The founders use their own funds to start the projects, sometimes accepting donations from personal contacts, and then develop their enterprise to be economically self-sustaining.

The sites chosen for the interviews are all prominent tourist towns. This is because (a) such places appeal to foreigners, as they have the infrastructure in place that provides convenience, resources and companionship in the new environment, and (b) for projects directed at tourists as consumers, these are the sites where most tourists go. None of the respondents in this study had a background in aid work as part of their previous paid career. No longer needing to earn a living in their home country, they have migrated to places where they believe they can 'make a difference.'

The paper begins by explaining the methodology of this research project. A descriptive summary of the participants and their projects follows. The discussion after that has two strands. The first strand is an exploration of the participants' agentic empowerment in choosing mobility for aid work as a retirement commitment. The second strand addresses the critics of aid workers as outsiders, charged with inherently performing in the manner of colonizers, so therefore effectively continuing a colonizing process.

The limitations of this study are acknowledged in the next section. The conclusion reiterates the participants' assertions of achieving emancipation through altruism and mobility. Their common goals are to (a) resist a stereotypical life as an ageing person in a western society, whilst (b) achieving purpose through helping others.

\section{Methodology}

The project illustrates that we live in an era when research into the experience of ageing can take place prospectively rather than retrospectively [13]. All participants in this study were happy to reflect on how the aging process was impacting on them. They had not yet reached very old age. I met them during their active post-retirement years. They illustrate that one's subjective age - how one feels! - may not correspond with assumptions about any chronological age [14]. My research involved interviews with western retirees in Cambodia, Laos and Myanmar during three six-week fieldtrips, in 2015, 2016 and 2019. Interviews took place in Phnom Penh, Battambang and Siem Reap (Cambodia), Luang Prabang (Laos) and in Bagan and Yangon (Myanmar). All participants were selected because they had moved to these locations upon retirement, and were now operating social justice projects.

A total of 20 people matching these two variables were interviewed. All were aged over 63 , and up to 76 years of age. They were asked about

- their decision to relocate

- about the projects they ran in their new domicile

- the contribution they believed they were making

- their general well-being and happiness compared with in their former situation.

Further key variables they held in common were

- all were fluent English speakers

- they had relocated after the age of 62 .

- they had chosen South East Asia as the location for their new life

- as they aged, they had wrestled with difficulties of continuing to live in their home country

- $40 \%$ still owned a home, usually a flat, in their home country, and expect to permanently depend on rent for income.

- A further $40 \%$ had 'sold everything' including their home, to fund their later years in South East Asia. 
- Most were single, with limited family ties. All, bar one, had arrived at their new location as single, divorced or widowed individuals. The one exception: a woman whose husband worked (paid) on an aid project in an adjacent country.

- Around two thirds were male, including two gay men.

- Three had adult children. One had a daughter also living in Cambodia. The other two had one adult child each, one in USA, and one in Japan. They explained that with Skype they could be in touch when they wished; that they, like their offspring, could be anywhere in the world.

- Not one person noted any religious affiliation driving their activities and motivations in their new role.

\section{The research took place via two approaches Prior to fieldwork}

The first stage of the methodology involved tracing - or trying to trace - people through expat clubs and website forums, prior to fieldwork. This process was carried out over several months. This (obviously!) yielded responses only from people who belong to such organisations. Whilst heavily engaged in social projects - dinner clubs, travel groups none of these people were involved in aid projects. Over 60 voluntary organisations and aid agencies which might host aged volunteers were also contacted, using various web sites and the Phnom Penh yellow pages as resources. This yielded just three interviews.

\section{During fieldwork}

The second approach relied on finding participants in the field. This was readily achieved by visiting cafes, restaurants and other businesses advertising a 'social good' role. The owner was always willing talk, either immediately, or at a call-back time later.

This approach yielded 17 participants. The casual encounters of a mobile researcher [15, 16] meshed with the daily activities of these people. The high number of respondents can be described as a function of the method. They could not have been located by any other means. These were individuals who did not join expat forums. Nor were they regular users of social media. They were hands-on at their social enterprise, and willing to speak with anyone who dropped by.

Social time was also spent with some of the participants in this study, such as additional casual conversations over drinks and meals. The result was an extremely rich collection of primary data. Personal, thoughtful and vibrant material was gathered. Occasionally conversations were recorded on digital tape. Where this was too difficult (noisy!) the researcher took notes, later in private enlarging the details.

D'Andrea's call for mobile methodologies suggest the following should be undertaken: at specific geographic locations the researcher must (a) identify and interpret practices that constitute hypermobile formations locally; (b) analysis of the socio-economic context of the subjects and communities; (c) explore multiple sites to enable identification of the connective character of hypermobile formations across diverse spaces [15]. Whilst this obviously worked, seeking respondents at particular locations is counter to my employing University's funding requirements. 'Fishing trips' where one hopes to find respondents, but cannot promise to, are not fundable. Hence the researcher set up her project under the guise of certainty of locating participants. This enabled her to comply with her university's compulsory Ethics Committee requirements.

\section{The participants: commentaries on aging and retirement}

Participants' commentaries on ageing and retirement included observations that 'this was 'the last window to do something good in the world'; that new projects 'give me the energy I never had, sitting around doing nothing at home'. Not one person indicated that chronological age might be a barrier to undertaking their work in South East Asia. Indeed, the obverse was true: their biological age enabled retirement, which gave them time to undertake their new ventures.

Several explained that singleness meant freedom to make major lifestyle changes at retirement without any need for negotiation with a partner or 'tied stayer' [17]. 'It would be nice to travel with a mate, but I cannot hang about waiting for someone to make up their mind' one man told me. Some referred to negative experiences as a single older person in their home country: to loneliness, isolation and being 'out of synch' in their home environment.

An Australian woman said, 'what are you supposed to do, as a retired single woman? Play bridge? Go shopping? That is all so pointless, compared with what I can do here.'

These retiree migrants were unfettered by any lack of 'belongingness or social embeddedness' of their prior location [18]. Through mobility, they constructed a new place to belong by creating a distinct niche in the new location. 
The lack of intimate family associations (or 'emotionally significant relationships' [19] afforded the liberty to access international mobility. Whatever the 'ambivalence and conflict' in a family network [18], if older people engaged with family and/or community, they may have less impetus to relocate. A negative association of strong family / work/ location ties and migration has been identified [17, 19]. A Canadian male participant in this study, aged 66, told me 'I never had a family. After an interesting international career, it means I am now totally free to do whatever I want, whereever I want. I can focus on what I believe is really it important!'

\section{Independent projects}

Most participants told the story of a visit to the region as a tourist a year or so before. They arrived again as retirees, saw a niche they could possibly fill, and were now running various charities and aid programmes. These included a workshop training and employing around 20 landmine amputees; a restaurant that trained and employed about10 deaf or other disabled people; schools of up to 600 extremely poor children; a computer lab for 55 teenage or adult students; a sewing studio employing 22 abused or disabled women; 22 bee keepers; a sustainable factory making dairy products and employing 35 people; and craft co-operatives selling the handwork of over 120 contributors, mostly people in rural villages.

None of the operators had employment histories that related to their present work. Nor were there long term plans to make the change in their 60 s to this kind of activity. They were energetically enacting their version of 'productive ageing' [4].

\section{Australian woman, 69}

'I came here nine years ago, celebrating retirement at 60. I met a local family and gave them a few English lessons. It all grew from there. We now teach and feed hundreds of children every day. I cannot see myself ever doing anything else.'

\section{Australian man, 71}

'I was a teacher and I got so fed up with the endless petty bureaucracies and idiotic politics. I hate Australia and its small minded, racist politicians. I'll never go back, even to visit. Here I am doing something useful, with absolutely wonderful people. It is a brandnew fabulous life.... I have a daughter in her 30s who is joining me this year. She'll be running the second restaurant.'

\section{British man, 72}

'My career was in finances. Then I came here on holiday. Eight years later I am running an organisation that feeds people, educates children, trains adults for work. Something magic happened.'

Each of these participants explained that it had not been a difficult decision to make this change. British man: 'The need is there. You can help. You just have to go and do what you can. You can't not go.' He explained that he had set up his enterprises so they would be self-sustaining well into the future. 'My management team, all local people: I have trained them so that they can take over and run everything. The same staff will always be employed, their children educated'.

Most referred to recent and current political events in their new country. For example, those interviewed in Cambodia expressed enormous empathy for a nation of survivors of the Khmer Rouge regime (1975 - 1979, during which time people were denied their rights, and almost 2 million Cambodians died). In Laos, more than 8000 people per year are new casualties of landmines; remnants of the two million tons of ordinances dropped their 1964-73. Myanmar continues its massive human rights and humanitarian crisis.

British man (above): 'We can never undo those atrocities. But we can try to ensure that at least some of the children today have a far better life'. To him it was common sense to help if one was able to. The Canadian running an artisan workshop for landmine amputees explained that these people would not find other employment. 'It affects their whole lives. If a farmer stands on the mine, his whole family is forced into even greater poverty. An amputee child has a very limited future'

These people were aware of 'voluntourism' projects aimed at retirees. (Voluntourism - a term referring to the combination of a travel holiday and voluntary work). But none had the least interest in this. Their concerns were that these were often unethical, and were aimed at profits for tour companies rather than for charities. 'They depend on the naivete of the volunteers', one person told me. Another said. 'They just sift people through, and take their money, so the tourists can go home with a 'feel good fuzzy'. This research group differed from tourists or other expat inhabitants for their full engagement with local people, working with them, living with them, speaking the local language. At a time when they had expected to be fully retired, they had found a new mission in life, one driven by their own values and 
sources of satisfaction, rather than by the strictures of the organisations that previously employed them - and that they had retired from.

Every person explained that the independent approach was essential, because of their distrust of formal aid agencies in these countries. They worried that the funds they wished to contribute could disappear into corrupt practices. Ideologically, they felt that too many organisations were being 'shaped by managerial preoccupations rather than moral imperatives or sentiments' [20]. Setting up their own projects ensured they maintained total autonomy and control. For them, a valuable new undertaking in life had been achieve through this mobility.

\section{DISCUSSION}

Two main themes are addressed in this discussion. First, the issue of retirees and agentic empowerment: through making a life changing decision they were escaping prescriptive expectations of aging individuals in their home culture.

Second, as retirees from advantaged countries, can their new roles in developing countries be seen as yet another form of colonialist interference? Are even such apparently well-intentioned social entrepreneurs to be suspected of something other than genuine altruism? [21].

\section{Agentic empowerment to find a purpose in life}

This project illustrates 'ageing and migration as entwined trajectories in a geographic- time life course' [10]. Throughout their working lives these participants had gone along with assumptions about eventual retirement. Everyone of them told me that their current life, and geographic place of domicile, was not what they ever imagined they would do in their late years. They had assumed fixity in one place, with perhaps some travel; but not a total re-location. Now, through their own efforts to make the most of their final active years, they were consciously defying 'the physical, behavioural, or social norms for an older person' [16]. They were determined to avoid the confines of an immobile life [15]. Hence they had 'made the decision' (a term many used, or 'I bit the bullet') and escaped a conformist old age. There was extensive talk not just of the limitations of achieving a satisfying life in their own familiar environment; or of their rejection of 'greedy' western values; but also of the drive to try to do something of value for other people in the world. A specific identifiable project was required, to retain high purpose as they aged [6]. For this group of people, developing countries provided opportunities to really make a difference.

For these retirees, lifestyle migration is an individualist narrative, about the transformation of self through movement' [19]. The quest for an enhanced lifestyle was a key motivator for that spatial mobility [22]. They had sought, and found, an alternative to being shoved into the marginalized status of older people, back home. Whilst each individual's personal circumstances were particular to them, the feature in common was that they had made a decision, and then acted on it.

The academic microscope lingering over the phenomenon of migrant retirees reveals how 'the mobilities paradigm and lifestyle intersect' [23]. It reiterates that 'multiple mobilities are entangled in social processes and structures' [24]. Those processes reflect the demise in the Western world of assumed values based of a stable location, extended family and inclusive community. For the participants of this study, it seemed that ageing was not such a problem, so long as they could be mobile. Mobility and financial independence gave them the opportunity to pursue activities that were inaccessible during their working lives. Images of old age involving inactivity, dependence, and physical and mental impairment, saturate populist versions of ageing. Isolation and loneliness were particular fears [18]. All of those possibilities were rendered redundant - were now irrelevant - to this cohort.

When theorising migration, the predominate paradigm has long been the push / pull model. The framework considers migration as the consequence of individuals' assessment of contextual factors of their present domicile, compared with potential future destinations: usually 'a discrepancy between their actual and desired living conditions' [25]. For participants in this new study, a pragmatic assessment of what they could offer was the key variable. Here, they could construct a worthwhile project around their available, or obtainable, resources. This could be described as positive voluntary migration; the opposite of reluctant relocation due to various stressors [25].

For elder relocaters, voluntary migration has also been theorised in relation to the life course [26, 4]. As people age, their activities and means also change and they might review options for the future. The retirees in South East Asia had the freedom to make significant new life changes. Most declared that they had 'escaped', claiming power through mobility [22]. They voted with their feet, passports and suitcases. Their new situation provided a re-invigoration, a repurposing of their life.

Rogaly explains that 'forms and aspects of mobility are bound up with unequal power relations' [27]. Yet through their mobility, this group had access to try to address local power relations: to do what they could to redress the balance, for even a handful of people. 
The restauranteur with disabled trainees explained that he knew he needed a new life, and wound up in Cambodia. Once there, he devised a useful role for himself: his skills would make a practical contribution to social justice. 'This is a business. Everyone who works here has to be better off than they would be otherwise. I train them so they have to earn money to send their children to school and buy those clothes. Otherwise there is no point running this.' He marvelled at the U turn in his life.' Like many, he said 'this was the best decision I ever made. I'd sooner grow old here, than anywhere else.'

\section{Colonialist? Altruistic? Humanitarian?}

It is easy for critical observers to reflect on westerners 'helping' disadvantaged people in developing countries, as 'colonialist' - an extremely negative connotation, implying that this is for their own power-seeking or material advantage. Certainly, the colonial legacy can still drive 'migratory imaginings', and a sense of entitlement to exercise continuities with the colonial past [4]. 'In previously colonised contexts... expatriate national identities can still be grounded in historical notions of racial and cultural superiority versus the local other' [1]. In international tourism, colonialist outlooks remain precisely because they are advantageous to travellers. The global power inequalities established during the European Empire and colonialism have provoked a continuing sense of privilege, including the freedom of international mobility by the citizens of richer countries, to poorer nations.

Various writers have addressed the recapitulation of colonialism as an inherent part of tourism by Westerners in former colonies [22-31]. Development policies and agencies are also charged with this [31]. These particular aid workers, like tourists, draw on the benefits of the power and fiscal inequality between their own country and that being visited. The same global patterns of inequality and poverty remain intact. This continues to reinforce the dominant position of the North [31]. Scholarly discussion about aid professionals refers to missionaries, mercenaries, misfits and 'selfish altruists'. The latter apparently self-contradictory term denies the possibility of any genuine selflessness, for the benefit of others. Careerist aid workers are gazed upon with suspicion about their motives and life style: the excess of some aid workers, and the morally questionable position of 'doing well out of poverty' [32]. There is ongoing debate about the role of altruism and professionalism among aid workers [32, 28, 11].

There are significant key difference between the subjects of Fechter's revealing ethnographic work on workers in aid agencies in Cambodia, and my ethnographic subjects considered here. For a start, the participants in my study are not in the process of building careers. In their 60s and older, all have all completed their careers - interestingly, every one of them in an arena unrelated to aid. They were in a position of not continuing to accumulatw assets, such as savings or property; they had already done so. Their new project involved disposal of previously-earned assets; they could now relinquish those material accumulations to benefit others. Their personal resources from home are funding their projects. In this way, they are making a direct transfer of wealth from a richer country to a poorer one.

Nor were they remotely interested in being part of any official agency, NGO or structured 'aid industry' organisation. Their goal was to maintain total control of how their resources were distributed, with none at all being creamed off by any 'official' administration or bureaucracy. None were overtly political in their new environment; rather, they carried out their work largely 'under the radar', in order to avoid any interference by any local authoritative body, as far as they could.

So how to reply to those academic authors who insist that a negative 'othering' of local people continues to inform aspects of development theory and practice? The only solution is to turn this around, and insist that a positive view of the potential of the so-called 'other' is fundamental to the establishment and success of the operations described here. From my interviews, discussions and observations during the field trips, it was clear that this cohort of westerners had genuine commitment to upskill some of the world's most disadvantaged people, to rescue them from extreme poverty. In answer to that accusation of 'colonialist', these social entrepreneurs were not trying to change the culture top down, or to take on any role at all of governance. This is not about any attempt to take over whole nations. Strategies towards structural change were not their agenda. It is about creating do-able projects at a local level, where the need desperate, and which would otherwise not take place. This process has been referred to as 'enlightened altruism'. 'A truly enlightened altruist would act with objectivity, with knowledge of the inevitable consequences of any response after carefully considering the problems at hand, and after deliberating on a global scale' [21].

The operators in this study were gaining success and satisfaction by working with small clusters of people, personally knowing each individual, and accommodating their individual needs. While personal motivation includes satisfaction at making a difference, that difference is the visibly heightened life chances of others. Their humanitarianism matches Palacious's review of colonialist critiques of volunteers working on aid projects: that 'the western intention of helping underlying the development aid goal is humanitarian as much as it is colonialist' [33]. Their efforts and agenda also correspond to the notion of 'moral labour': a desire to support others, not as in contrast or even in tension with professional activities, but as an integral part of them [20]. 


\section{RESEARCH LIMITATIONS}

The limitations inherent to this project require acknowledgment. Issues and themes that emerged from this investigation are diligently stated and analysed, and understood to accurate for these participants; but only for these people. The findings cannot be generalised to other foreign retirees, either at these locations, or anywhere else.

- The foremost obvious constraint is the selection of participants who have been labelled 'westerners'. This was because the researcher speaks only English.

- It is worth acknowledging the ambiguity of the term 'ageing'. Whatever a person's chronological age, their psychological attitude to ageing, and their subjectivity around their own experience of the ageing process, may give people of the same years, a different notion of their own ageing [14]. For the people in this study, their age at the time of this research was simply the fact at that moment. They were doing what they could, while they could - an acknowledgement that their physical and psychological abilities may diminish over time.

- Finding individuals to interview was indisputably haphazard. There is no reliable 'scientific' way to construct such a sample.

- The sample size was small. There is no scope to develop data to show variables according to gender, nationality or present domicile.

- The fieldwork depended on the researcher herself. Her age and ethnicity (similar to that of the participants) were likely advantages.

- When interviews are used as a data base, then what one is told is the currency. Participants sometimes revealed private information, which could not be reported. As always in field interviews, the interviewees construct the narrative, which is coloured by their own interpretation, predispositions and decisions. They can omit any information. There is no means of verifying, disproving or challenging their narratives.

- It is inevitable that the interviewer, too, will bring assumptions and biases to the choice of questions, which may impact on the interviewee's replies.

- Temporality: every participant expected that their new lifestyle would be transformative [22]. A longitudinal study was not possible for this researcher. A subsequent interview every few years with the same people, into their 80 s and 90s, would reveal how their future expectations (about staying in South East Asia 'forever') played out.

- This was a study of people who were living in Cambodia, Myanmar and Laos. The research process did not retirees who may have arrived to try this way of life, but who had then left.

To reiterate: every one of these retiree migrants were living in a different country, and with different activities, than during their prior careers. This study is a snapshot only these particular individuals, in this region.

\section{CONCLUSION}

This paper has attempted to combine insights from the literature on well-being during ageing, with the impacts and critiques of social justice entrepreneurship in developing countries. The retiree participants in this study are exemplars of the 'rejection of conclusive, all-encompassing statements of what it means to grow old' [34]. As part of the world's privileged, they enjoy good health and can expect greater longevity than previous generations. Travel is not a mystery to them; if the home nation has become objectionable, meaningless or just boring, then it may be time to move. Applying their mobility and using their energies to meaningful projects that support and empower others, provides their own sense of worth in the world. Those skills and knowledge collected over a lifetime: here is a place where these can make a significant difference in peoples' lives. Their 'new life purpose' passes onto those they assist, for whom the benefits are profound.

The interventions discussed in this paper defy critics of well-meaning initiatives established by altruistic foreigners. When detractors suggest that NGOs are a better route for local poverty rescue, they are missing the value and power of the intimacy and immediacy that occurs in these enterprises. For local people, the achievement of useful employment gives the chance to participate more fully with their communities, whilst enjoying personal independence and fulfilment, and furthering the life chances of their families. Meanwhile, these social entrepreneurs combine their own need for a worthwhile mission as they age, with establishment of successful models for other such projects.

\section{REFERENCES}

1. Kunz, S. (2016). 'Mobilities: Locating the Expatriate in Migration Scholarship' Geography Compass, 10(3); 89-101.

2. Wahl, H. W., Deeg, D., \& Litwin, H. (2016). Successful ageing as a persistent priority in ageing research.

3. Pietilä, I., Calasanti, T., Ojala, H., \& King, N. (2017). Is retirement a crisis for men? Class and adjustment to retirement. Men and Masculinities, 1097184X17724189.

4. Bengtson, V. L., \& DeLiema, M. (2016). Theories of aging and social gerontology: Explaining how social factors influence well-being in later life. Gerontology: Changes, Challenges, and Solutions [2 volumes]: Changes, Challenges, and Solutions, 25. 
5. Flicker, L. (2018). Successful or Healthy Ageing. Journal of the Indian Academy of Geriatrics, 14.

6. Pinquart, M. (2002). Creating and maintaining purpose in life in old age: A meta-analysis. Ageing international, 27(2), 90-114.

7. Rowe, J. W., \& Kahn, R. L. (1997). Successful ageing. Conceptual expansions for the $21^{\text {st }}$ century. The Gerontologist, 37(4), 593 - 596.

8. Tiilikainen, E., \& Seppänen, M. (2017). Lost and unfulfilled relationships behind emotional loneliness in old age. Ageing \& Society, 37(5), 1068-1088.

9. Ardelt, M. (1997). Wisdom and life satisfaction in old age. The Journals of Gerontology Series B: Psychological Sciences and Social Sciences, 52(1), P15-P27.

10. Lulle, A., \& King, R. (2016). Ageing Migrants: A New Research Challenge. In Ageing, Gender, and Labour Migration (pp. 1-25). Palgrave Pivot, New York.

11. Paragi, B. (2017). 'Contemporary Gifts: Solidarity, Compassion, Equality, Sacrifice, and Reciprocity from an NGO Perspective’ Current Anthropology, 58(3), 317-339.

12. Harrison, D., \& Schipani, S. (2007). Lao tourism and poverty alleviation: Community-based tourism and the private sector. Current issues in tourism, 10(2-3), 194-230.

13. Wright, R. (2015). What a drag it is getting old: Awareness and appraisal of age related change in white men born between 1946 and 1955 (Doctoral dissertation, Wichita State University).

14. Robson, D. (2018). 'The age you feel means more than your actual birthdate'. https://www.bbc.com/future/article/20180712-the-age-you-feel-means-more-than-your-actual-birthdate

15. D'Andrea, A. (2006). 'Neo-nomadism. A Theory of post indentitarian mobility in the global age.' Mobilities, 1(1): $95-120$.

16. Vannini, P. (2010). Mobile cultures: from the sociology of transportation to the study of mobilities. Sociology compass, 4(2), 111-121.

17. Mulder, C. H., \& Malmberg, G. (2014). Local ties and family migration. Environment and Planning A, 46(9), 21952211.

18. de Jong Gierveld, J., Van Tilburg, T., \& Dykstra, P. A. (2006). Loneliness and social isolation. Cambridge handbook of personal relationships, 485-500.

19. Green, P. (2015). Mobility, subjectivity and interpersonal relationships: older, Western migrants and retirees in Malaysia and Indonesia. Asian Anthropology, 14(2), 150-165.

20. Fechter, A. M. (2016). Aid work as moral labour. Critique of Anthropology, 36(3), 228-243.

21. D’Souza, J. F., \& Adams, C. K. (2014). On unenlightened altruism. Journal of Human Values, $20(2), 183-191$.

22. Botterill, K. (2017). Discordant lifestyle mobilities in East Asia: Privilege and precarity of British retirement in Thailand. Population, Space and Place, 23(5), e2011.

23. Thulemark, M., Duncan, T., \& Cohen, S. (2013). Lifestyle mobilities: Conclusions and future research. Lifestyle mobilities: Intersections of travel, leisure and migration, 253-260.

24. Hui, A. (2016). 'Dialogue between Migration and Mobility Research' www.tandfonlibe.com.doi/full/10.1080/17450101.

25. Smetcoren, A. S., De Donder, L., Dury, S., De Witte, N., Kardol, T., \& Verte, D. (2017). Refining the push and pull framework: identifying inequalities in residential relocation among older adults. Ageing \& Society, 37(1), 90-112.

26. Davies, A., \& Hoath, A. (2016). The Migration of A ustralians to B ali, I ndonesia: More than Retirees and Surfers. Geographical Research, 54(1), 35-51.

27. Rogaly, B. (2015). Disrupting migration stories: Reading life histories through the lens of mobility and fixity. Environment and Planning D: Society and Space, 33(3), 528-544.

28. Carbonnier, G. (2015). Reason, emotion, compassion: can altruism survive professionalisation in the humanitarian sector?. Disasters, 39(2), 189-207.

29. Bell, C. (2016a). 'The Best Exotic Marigold Hotel. International Retirement Migration on Film.' _Journal of Ageing and Society. Ageing and Society DOI: https://doi.org/10.1017/S0144686X1600057X

30. Bell, C. (2012). 'Cultural tourism and tourism culture: safari lodges in Namibia'. In: Leisure and Tourism: Cultural Paradigms, Editors J. Dodd and V. Sharma. Jaipur, India, Rawat Publishers

31. Escobar, A. (2012). Encountering Development: The Making and Unmaking of the Third World. USA: Princton University Press.

32. Fechter, A. M. (2012). 'Living Well'while 'Doing Good'?(Missing) debates on altruism and professionalism in aid work. Third World Quarterly, 33(8), 1475-1491.

33. Palacios, C. M. (2010). Volunteer tourism, development and education in a postcolonial world: Conceiving global connections beyond aid. Journal of sustainable tourism, 18(7), 861-878.

34. Carr, A., Biggs, S., \& Kimberley, H. (2015). Ageing, diversity and the meanings of later life. Contemp. Readings L. \& Soc. Just., 7, 7. 